\title{
Prostate Cancer Outcomes Study
}

National Cancer Institute

\section{Source}

National Cancer Institute. Prostate Cancer Outcomes Study. NCI Thesaurus. Code C16166.

A study initiated in 1994 by researchers at the National Cancer Institute (NCI) to look at the impact that treatments for primary prostate cancer have on the quality of life of patients. PCOS is the first systematic evaluation of health-related quality-of-life issues for prostate cancer patients conducted on a multiregional scale. 